\title{
QUALITY INDICATORS FOR MEASURING THE LEVEL OF PATIENTS' INVOLVEMENT IN THE PHARMACEUTICAL CARE PROCESS
}

\author{
KATARINA M. VUČIĆEVIĆ ${ }^{1}$, JOHAN J. DE GIER ${ }^{2}$, JUSTYNA DYMEK ${ }^{3}$, NICO KIJLSTRA ${ }^{4}$, \\ SABINE WALSER $^{5 *}$, SILVIA RAVERA ${ }^{5}$, and BRANISLAVA MILJKOVIĆ ${ }^{1}$
}

${ }^{1}$ Department of Pharmacokinetics and Clinical Pharmacy, The University of Belgrade - Faculty of Pharmacy, Belgrade, Republic of Serbia

${ }^{2}$ Unit of Pharmacotherapy, Epidemiology \& Economics, Groningen Research Institute of Pharmacy, University of Groningen, Groningen, the Netherlands

${ }^{3}$ Department of Social Pharmacy, Faculty of Pharmacy, Jagiellonian University Medical College, Krakow, Poland

${ }^{4}$ Health Care Inspectorate, Ministry for Health, Welfare and Sport, Utrecht, the Netherlands ${ }^{5}$ European Directorate for the Quality of Medicines and HealthCare (EDQM), Council of Europe, Strasbourg, France

\begin{abstract}
Patient-centred counseling is an integral part of the pharmaceutical care process. Quality indicators can be valuable tools to measure the level of patients' involvement in their personal healthcare. The aim of the study was to validate two quality indicators for community pharmacy care focusing on patient involvement. As part of the EDQM Pharmaceutical Care Quality Indicators Project (Council of Europe), at least 10 patients per indicator were recruited in each community pharmacy in Serbia and Poland. Pharmacists targeted patients aged 18-65 years starting chronic treatment (Indicator 1) and elderly patients with polymorbidity receiving at least five chronic treatment medicines (Indicator 2). Based on patients' answers to a questionnaire, patient-pharmacist consultations took place. For Indicator 2, patients were also offered a medication review. In total, $66 \%$ of Serbian patients and $29 \%$ Polish patients, for Indicator 1, were engaged in pharmacist-patient consultations; $96 \%$ of Serbian and $84 \%$ of Polish elderly patients subsequently participated in medication reviews. Community pharmacists can increase patients' involvement in their own pharmaceutical care, and there is a need for such services. This study defines a pragmatic approach to encourage/support the implementation of the pharmaceutical care philosophy and working methods in European community pharmacies.
\end{abstract}

Keywords: patient participation, patient counseling, therapy outcome, medication review, medication use

Healthcare services of high quality ought to be provided to an individual patient to increase the likelihood of desired health outcomes. Quality indicators are tools used to measure and improve the quality of healthcare (1). There are few studies describing sets of quality indicators for community pharmacy care; however, these indicators have been developed and tested in specific national healthcare systems (2-4).

The European Committee on Pharmaceuticals and Pharmaceutical Care (CD-P-PH), coordinated by the European Directorate for the Quality of Medicines and HealthCare (EDQM) (Council of Europe), contributes to improving public health and access to good quality medicines and healthcare by developing harmonized provisions and practices for the rational use of medicines and promoting the implementation of the pharmaceutical care (PC) philosophy and working methods in Europe (5). The CD-P-PH's activities in the PC domain are carried out with the support of one of its subordinate committees, the Committee of Experts on Quality and Safety Standards in Pharmaceutical Practices and Care (CD-P-PH/PC). In 2008, the CD-P-PH/PC commissioned a survey on key concepts in $\mathrm{PC}$ and performance indicators used to evaluate the quality of $\mathrm{PC} /$ services in the Council of Europe member states (6). Based on the conclusions of the survey report, further development, testing, and implementation of a basic, generally applicable set of PC indicators was

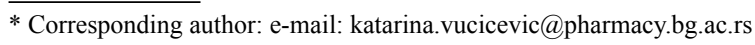


recommended (6). Therefore, since $2008 \mathrm{CD}-\mathrm{P}-\mathrm{PH} /$ $\mathrm{PC}$ has been working on the 'EDQM Pharmaceutical Care Quality Indicators Project', aiming to design indicators to assess the quality of PC in Europe. In 2011-2012 five sets of indicators were defined focusing on different PC areas (7). In 2013-2014 the $\mathrm{CD}-\mathrm{P}-\mathrm{PH} / \mathrm{PC}$, coordinated by the EDQM and with the support of the Quality of Pharmaceutical Care Indicators Working Party, carried out a multinational validation study.

One of the essential areas in the PC model in community pharmacy is patient counseling. During the conversation with patients, the pharmacist can determine what they understand about drug therapy and what concerns they may have (8-10). For the pharmacist, this will lead to a translation of patientrelated needs into a problem-solving format. Review of medicines is an essential component of the PC process which can minimize the number of drug-related problems (DRPs) and resolve therapy problems. Medication review is particularly relevant in elderly patients (11-14).

Consequently, one of four PC key areas identified by the Committee of Experts CD-P-PH/PC focused on the measurement of the level of patient involvement in the PC process and was entitled Structured patient-pharmacist consultations (chronic therapy, poly-pharmacy, poly-morbidity) via 'My CheckList' (Topic Group (TG) 3). 'My CheckList' is a form where patients can write down their expectations, concerns, experience with the use of their medicines and questions to be discussed with the pharmacists. Two specific indicators were included in the TG3 study, evaluating the following items: documented counseling provided by a pharmacist during patient-pharmacist consultation based on 'My CheckList' at the start of a new chronic treatment (Indicator 1) and documented medication review in elderly patients (suffering from multi-morbidity and receiving polypharmacy) having attended a 'My CheckList' consultation (Indicator 2) (15).

\section{Aim of the study \\ This paper describes TG3 activities that aimed to validate the quality indicators in community phar- macy settings in two European countries and to eval- uate the views of pharmacists about the usefulness of the indicators.}

\section{Ethics approval}

The local ethical committees approved the study, and the studies were performed in accordance with the Declaration of Helsinki.

\section{Methods \\ Study settings}

Prospective pilot studies were performed during 2013-2014 in community pharmacies located in both urban and rural areas of Poland and Serbia.

The pilot studies were managed by a TG leader and carried out by national coordinators who organized and managed research activities at the local level. Study materials, including instructions, letters for pharmacists and patients, and data collection forms for pharmacists and patients, originally prepared in English as provided by the TG leader (15), were translated into Polish and Serbian. The translation of the completed forms into English was likewise conducted.

\section{Quality indicators testing}

In Serbia, the invitation to participate in the study was announced on the website and in the official journal of the Pharmaceutical Chamber of Serbia. In Poland, pharmacists were recruited via face-toface contacts and via mailings and letters to registered pharmacists. Community pharmacists voluntarily agreed to join the study and confirmed their participation by signing an agreement form.

Patients were informed about the purpose of the study, and their participation was voluntary and free of charge. Inclusion criteria for patients in Indicator 1 validation were: $18-65$ years, and having been prescribed for the first time during the previous 12 months medication for chronic use (duration of therapy: minimum 6 months) that belongs to one of the following group of drugs: cardiovascular, alimentary tract and metabolism, musculoskeletal, respiratory system. Inclusion criteria for patients in Indicator 2 validation were: $\geq 65$ years, suffering from multi-morbidity, and hence, being prescribed at least five medications for chronic conditions belonging to the previously mentioned groups of drugs. Overall, patients not eligible for enrolment in the study were those with whom the pharmacist could not make personal contact, physically frail elderly patients, patients receiving palliative care, and those with cognitive impairment.

At the first dispensing of a newly prescribed medicine (Indicator 1) or when medicines for longterm treatment were dispensed (Indicator 2), patients were invited to participate in the study and, if they agreed, they received one 'My CheckList' form. They were asked to fill in the form at home, and bring it to a scheduled consultation (within 2-4 weeks) with the pharmacist. After the consultation, based on the patient's answers in 'My CheckList' and the patientpharmacist discussion, the pharmacist was expected 
to summarise the main aspects and the outcomes of the consultation in the 'Consultation form for pharmacist'. Moreover, for Indicator 2, at the end of the patient-pharmacist consultation, if necessary, a medication review consultation was offered to the patients. The medication review was performed in line with the template proposed by the TG leader and focused on all medications that the patient used (prescription and non-prescription medicines). During the medication review process, the pharmacist, in cooperation with the patient, was asked to identify the person in charge of resolving/taking care of the identified issues and, whenever applicable, state whether the proposed actions were accepted or not by the identified person. At the end of the study, pharmacists were asked to complete a 'Questionnaire for pharmacists' aimed at collecting general information regarding the pharmacy and their views about the indicators under evaluation.

\section{Data analysis}

All data were collected anonymously. Measurements for assessing patients' participation in the PC process were calculated as follows:

Indicator 1: a) Number of documented patient counseling recommendations compared to the total number of patients receiving 'My CheckList'.

b) Number of documented counseling recommendations during 'My Check-List' consultation with at least one positive outcome (based on pharmacist's assessment) compared to the total number of patients receiving 'My CheckList' (for Indicator 1) (this additional calculation was performed to ensure that only fruitful consultations were actually considered for the Indicator 1 calculation).
Indicator 2: Number of documented medication reviews for patients having attended a consultation with a pharmacist compared to the total number of patients who attended a 'My CheckList' consultation (for Indicator 2).

Descriptive statistics analysis was performed with IBM SPSS Statistics (version 22).

\section{RESULTS}

In the pilot study conducted in Serbia, 70 pharmacies agreed to participate in the study and 64 of these (response rate: $91.4 \%$ ) returned the completed data collection forms, while in Poland response rate was $22.7 \%$ (5 out of 22 ). The majority of the participating pharmacies were located in cities with a population of over 150.000 inhabitants. In total, $30 \%$ of the community pharmacies participating in this study were located in towns with a population of $150.000-1.000 .000,25 \%$ in cities with more than 1.000 .000 inhabitants, $23 \%$ in towns between $50.000-150.000$, whereas $18 \%$ were located in smaller towns (10.000-50.000) and only $4 \%$ in towns with less than 10.000 people. Around $75 \%$ of the participating community pharmacies serve a population below 7.000 patients: $16 \%$ have $5.000-7.000$ patients, $42 \%$ have between $3.000-5.000$ patients, and $19 \%$ serve less than 3.000 patients. In total $14 \%$ of the recruited community pharmacies had 12.000 15.000 patients, whereas $9.000-12.000$ and more than 15.000 patients represented $5 \%$ of the remaining participating pharmacies. Only $30 \%$ of the community pharmacies stated to have a separate consultation room, and the average number of staff members

Table 1. Pharmacists' assessment of the outcomes of the patient-pharmacist consultation.

\begin{tabular}{|c|c|c|c|c|}
\hline \multirow{2}{*}{ Answer } & \multicolumn{3}{|c|}{ Percent of answers } \\
\cline { 2 - 5 } & \multicolumn{2}{|c|}{ Indicator 1 } & \multicolumn{2}{c|}{ Indicator 2 } \\
\cline { 2 - 5 } & Serbia (N=845) & Poland (N = 21) & Serbia (N = 1043) & Poland (N = 36) \\
\hline $\begin{array}{c}\text { 1. Patient better understood the use of the } \\
\text { prescribed drugs }\end{array}$ & 51.1 & 38.1 & 39.0 & 36.1 \\
\hline 2. Identification of the potential side effects & 16.7 & 23.8 & 14.8 & 16.7 \\
\hline $\begin{array}{c}\text { 3. Identification of non-adherence to the } \\
\text { therapy }\end{array}$ & 9.2 & 4.8 & 11.1 & 5.6 \\
\hline $\begin{array}{c}\text { 4. Patient referred to the general practitioner } \\
\text { because of side effects }\end{array}$ & 4.9 & - & 8.5 & 5.6 \\
\hline $\begin{array}{c}\text { 5. Patient referred to the general practitioner } \\
\text { because of non-adherence }\end{array}$ & 2.1 & 4.8 & 5.3 & 2.8 \\
\hline 6. Other & 11.8 & 28.6 & 16.8 & 30.6 \\
\hline 7. No major outcome & 0.2 & - & 1.8 & 2.8 \\
\hline 8. Do not know & 0.5 & - & 0.1 & - \\
\hline 9. Not filled in & 3.4 & - & 2.6 & - \\
\hline
\end{tabular}


was 5.95+/-3.66 (median 5). Due to the differences in the number of pharmacies involved in the project between the two countries, and the rather small sample size in Poland, statistics were performed separately for each country, and comparisons between countries were deemed not to be appropriate. Detailed analyses of patients' answers are included in the final report of the EDQM Pharmaceutical Care Quality Indicators Project (15), while this manuscript only focuses on the calculation of the 2 indicators under evaluation and the overall feedback received from pharmacists in this respect.

\section{Indicator 1}

In Serbia, 826 'My CheckList' forms were provided to patients and 542 patient-pharmacist consultations took place (66\%). In Poland, 10 patients (out of 34) were involved in a consultation with their pharmacist (29\%), as given in Figure 1.

Pharmacists' assessments of the outcome(s) of the patient-pharmacist consultation are summarised in Table 1.

The approximately same number of documented counseling recommendations had at least one positive outcome compared to the total number of patients receiving 'My CheckList': 92\% and 90\% for Serbia and Poland, respectively (Figure 1).

\section{Indicator 2}

In Serbia 549 'My CheckList' forms were handed out to patients with multi-morbid chronic conditions and 529 of these patients were involved in the medication review process (96\%), whereas in Poland 19 forms were handed out and 16 medication reviews were performed (84\%).

Various DRPs were identified during the medication review process (1144 in Serbia and 15 in Poland) including $14.9 \%$ and $16.7 \%$ drug-drug interactions, $14.3 \%$ and 5.6\% inappropriate drugs, $13.6 \%$ and $22.2 \%$ adverse drug reactions, $13.5 \%$ and $11.1 \%$ inappropriate dose and/or dosing interval, 11.4\%

a)

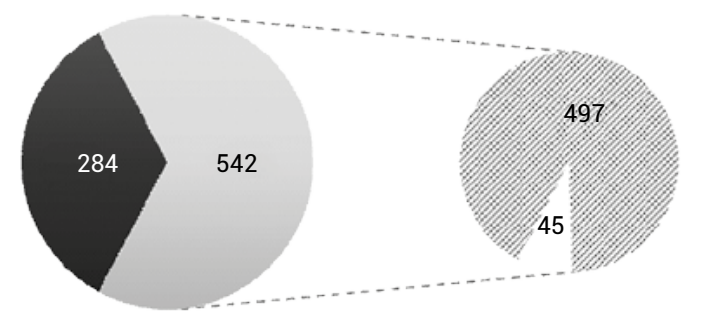

and $11.1 \%$ additional therapy needed in Serbia and Poland, respectively (all other answers accounted for $<10 \%$ ). In total, 1241 and 18 actions were proposed by Serbian and Polish pharmacists, respectively, with a view to resolving the DRPs identified during the medication reviews (examples of proposed actions: regimen adjustment, drug change, medical examination). Pharmacists assumed that $28.6 \%$ (Serbia) or $46.4 \%$ (Poland) of DRPs could be resolved with patients' involvement. In both countries, the person in charge of considering the identified issues accepted the majority of the proposed actions (Serbia: 67.1\%; Poland: $83.3 \%$ ).

\section{Pharmacists' feedback}

Overall, $87.5 \%$ and $100 \%$ of community pharmacists in Serbia and Poland, respectively, found 'My CheckList' useful in everyday practice, mainly in the case of polypharmacy patients receiving chronic treatment.

\section{DISCUSSION}

Two-way communication between patient and pharmacist is vital to the idea of patient-centered care and patient participation in the healthcare process, as patients are expected to ask questions, talk to the pharmacist and understand their condition and therapy. This pilot study was part of the EDQM Pharmaceutical Care Indicators Project.

As the main barrier to effective communication is time available for pharmacists to spend with patients, the model we have used in our study seems appropriate as almost all community pharmacists who participated in the research project found the approach useful for their daily practice. It splits the PC consultation process into two or potentially three meetings, and it gives patients enough time to contemplate and formulate the issues they are most concerned about and include information they require about the therapy on the form. At the same

b)

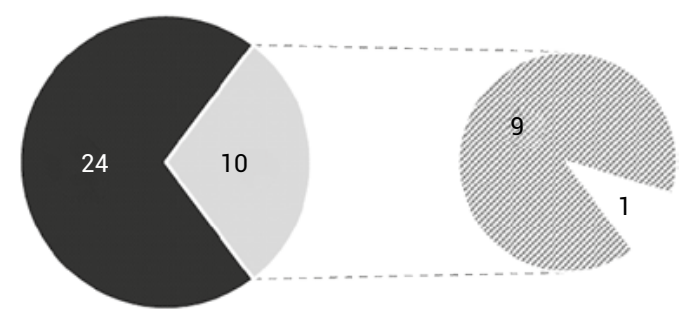

Figure 1. Total number of patients receiving 'My CheckList' (sum of dark and light grey), number of documented patient-pharmacist consultations (light grey), and number of documented counseling recommendations with at least one positive outcome (shaded) after pilot testing of Indicator 1 in a) the Republic of Serbia, b) Poland. 
time, during the consultation process, the pharmacist can better understand a patient's worries, potential issues, and DRPs from the form and the counseling is going to be more effective, focused on problem-solving, and directed towards the patient's needs.

Patient involvement and participation in $\mathrm{PC}$ can be challenging, but it is essential as it facilitates the achievement of meaningful and effective therapeutic outcomes (16). Based on our results, a large percentage of patients attending Serbian community pharmacies were willing to become more involved in their therapy management. On the contrary, in Poland the response rate was lower, indicating that engaging patients could be more delicate and difficult here. Such results might be attributable to the fact that relatively few patients were approached due to the heavy workload in community pharmacies, as the current daily practice does not include PC services. Moreover, patients who were enrolled in the study, perhaps, did not completely understand the benefit of the form and the consultation with their pharmacist. Therefore, it can be concluded that, in order to facilitate effective patient participation in the $\mathrm{PC}$ process, patients need to understand the purpose and added value of the partnership with their pharmacists, as well as their role in achieving better therapy outcomes, as previously mentioned (17). Additionally, it goes without saying that good communication and interpersonal skills during the consultation are required to establish positive healthcare professional-patient relationships and deliver highquality patient-centered care (18).

Targeting patients who are going to benefit the most from the service seems to be another important issue. Patients' acknowledgment of their chronic disease may be associated with difficulties in adjusting to the limitations that the condition imposes on their everyday life. Introducing a new medicine for long-term treatment can be delicate, as a patient has to decide whether he is going to take the prescribed medicine(s). Likewise, elderly patients with multimorbidity on chronic polypharmacy often require specific attention to make certain that the treatment goals are being met. Therefore, the indicators under consideration successfully responded to the patients' needs and contributed to the responsible and safe use of medicines in such populations, as previously published (8-10). In addition, it is evident that 'My CheckList' was discrete enough to provide information for the evaluation of actual and potential DRPs that would lead to targeted interventions by pharmacists. Furthermore, almost all pharmacists involved in this study indicated that the outcome of the consultation was positive for the patient (Table 1). This is indicative of the quality of the PC service in our study.

Active patient participation is required for the medication review $(17,19)$. In this study, an assessment of the patients' pharmacotherapy was performed for a large percentage of elderly patients after the initial consultation with the pharmacist. This indicates that patients perceived the importance and the value of the initial conversation with their pharmacist. This highlights the importance of the patient's positive experience during the first contact with the pharmacist. Therefore, patient follow-up should be considered in a systematic manner, as PC is a continuous cycle of needs assessment, care planning, and interventions to resolve DRPs.

With respect to the medication review process, it is interesting to note that the results of this study indicate that several DRPs were identified in pharmacist-conducted medication reviews and that the overall acceptance of the actions proposed to resolve these DRPs was high (67.1\% and 83.3\% acceptance in Serbia and in Poland, respectively). These outcomes provide further support for the hypothesis that medication reviews are an effective tool for the identification of drug-related problems and can play an important role in improving the quality and safety of the medication process. Finally, while substantially larger studies would be required to confirm the long-term positive clinical and economic benefits of pharmacist-led medication reviews, our findings suggest a need for greater integration of this service into primary care provision (20-22).

Despite these promising results, the generalisability of the study outcomes is subject to certain limitations. First, given the limited number of countries involved in our study, and the small sample size in one of them (which was a limitation in performing a statistical analysis to test differences in observations between two countries), the validity of the indicators under evaluation could not be fully evaluated. Second, there was an open call to recruit study participants; as a consequence, it could be argued that more motivated pharmacists and patients agreed to join the research project, and therefore, recruitment bias cannot be ruled out. Third, studies and several reviews conducted on the subject have shown that successful patient-centered care requires the collaboration of patients and their healthcare providers (23-25). The fact that our study did not involve collaboration between pharmacists and other members of the healthcare team means that only a partial contribution to the provision of comprehensive and in-depth patient care was possible. 
Finally, it is important to bear in mind that no patient follow-up was carried out after the pharmacists' interventions.

Notwithstanding the above limitations, the results of this study define a pragmatic approach to encourage and support the implementation of the PC philosophy and working methods in community pharmacy settings in Europe. Consequently, Indicators 1 and 2 can be implemented and used by national policy-makers and healthcare professionals to assess the quality of specific PC activities and policies, as they seem to be practical and straightforward to use in daily practice.

Finally, it is important to bear in mind that the implementation of the PC philosophy and the use of quality indicators in community pharmacy practice in European countries might not be straightforward and instantaneous; it requires time, political will, support, and collaboration with the prescribers and other key stakeholders involved in the medication management process. Nevertheless, in Serbia, new legislation focusing on good pharmacy practice in community and hospital pharmacy settings was adopted and came into effect from $1^{\text {st }}$ April 2021 (26). The above legislation is in compliance with the appropriate guidelines of the International Pharmaceutical Federation (FIP) and World Health Organization (WHO), including standards of PC services. Among others, counseling and medication review services are the core of this country-specific legislation. We are confident that this study, together with other professional and research activities, contributed to the overall position of PC standards in good pharmacy practice. In Poland, the pharmacist may provide PC service as supported by Polish law for a long time (including the period when this research has been performed) (27). Since December 2020, the act on the pharmacist profession describes in detail what PC is. This act lists the activities performed by a pharmacist: pharmaceutical consultations, medication reviews, developing an individual PC plan, performing diagnostic tests, and issuing prescriptions as part of the continuation of a medical order (27). However, these services are not provided in pharmacies regularly yet. At that time, Polish law allowed a pharmacist to provide pharmaceutical care.

\section{CONCLUSIONS}

The outcomes of our research substantiated the hypothesis that our indicators have the potential to play a considerable role in the involvement of specific patient groups in the PC process in community pharmacies. This information can be used to encourage their implementation in daily practice with a view to achieving the best medication outcomes for patients. The importance of the study lies in the fact that, among other documents, the conclusions and recommendations of the EDQM Pharmaceutical Care Quality Indicators Project were considered and taken into account in the drafting process of Council of Europe Resolution CM/Res(2020)3 on the implementation of pharmaceutical care for the benefit of patients and health services, which was adopted by the Council of Europe Committee of Ministers in March 2020 (28).

\section{Acknowledgments}

The authors would like to thank Prof Dr. Frank Eggert, Institute of Psychology, TU Braunschweig Braunschweig, Germany for the statistical analysis. The authors would also like to acknowledge all the delegates of the Committee of Experts on Quality and Safety Standards in Pharmaceutical Practices and Care (CD-P-PH/PC). Finally, the authors would like to thank all community pharmacists and patients who participated in the study for their time and invaluable support.

\section{Funding acknowledgments}

The current study was carried out within the scope of the EDQM Pharmaceutical Care Quality Indicators Project which was set up by the Committee of Experts on Quality and Safety Standards in Pharmaceutical Practices and Care (CD-P-PH/PC). The project was coordinated and supported financially by the Council of Europe's European Directorate for the Quality of Medicines and HealthCare (EDQM), Strasbourg (France).

\section{Disclaimer}

This manuscript was prepared by the authors in their personal capacity. The opinions expressed in this article are the authors' own and do not necessarily represent the views of their employers or of the Council of Europe/EDQM. The current article is part of a larger report encompassing the whole EDQM Pharmaceutical Care Quality Indicators Project (available at: https://register.edqm. eu/freepub).

\section{Conflict of interest}

The authors declare no conflicts of interest. 


\section{REFERENCES}

1. Campbell S.M., Braspenning J., Hutchinson A., Marshall M.N.: BMJ 326, 816 (2003).

2. Teichert M., Schoenmakers T., Kylstra N., Mosk B., Bouvy M.L., et al.: Int. J. Clin. Pharm. 38, 870 (2016).

3. Schoenmakers T.W., Teichert M., Braspenning J., Vunderink L., De Smet P.A., et al.: J. Manag. Care Spec. Pharm. 21, 144 (2015).

4. Winslade N., Taylor L., Shi S., Schuwirth L., Van der Vleuten C., et al.: BMC Health Serv. Res. 11, 12 (2011).

5. European Committee on Pharmaceuticals and Pharmaceutical Care (CD-P-PH) - EDQM (Council of Europe). Background \& Mission CD-P-PH. (cited 31.05.2018).

6. https://www.edqm.eu/en/pharmaceutical-caresurveys-and-reports (2009).

7. https://www.edqm.eu/medias/fichiers/policies and_practices_for_a_safer_more_responsibl.pdf (2012).

8. Kovacevic S.V., Miljković B., Vučićević K., Ćulafić M., Kovačević M., et al.: Patient Educ. Couns. 100, 1714 (2017).

9. Vucicevic K.M., Miljković B.R., Golubović B.C., Jovanović M.N., Vezmar Kovačević S.D., et al.: Eur. J. Gen. Pract. 24, 19 (2018).

10. Geurts M.M., Zuydgeest I.A., Walser S., Kijlstra N.B., Petkova V., et al.: Int. J. Pharm. Pract. 22, 186 (2014).

11. Rhalimi M., Rauss A., Housieaux E.: Int. J. Clin. Pharm. 40, 109 (2018).

12. Kovacevic S.V., Miljković B., Ćulafić M., Kovačević M., Golubović B., et al.: J. Eval. Clin. Pract. 23, 860 (2017).
13. Kovacevic S.V., Simišić M., Stojkov Rudinski S., Ćulafić M., Vučićević K., et al.: PLoS One9, e95536 (2014).

14. Tallon M., Barragry J., Allen A., Breslin N., Deasy E., Moloney E., et al.: Eur. J. Hosp. Pharm. 23, 16 (2016).

15. https://store.edqm.eu/index.html (2017).

16. Allemann S.S., van Mil J.W., Botermann L., Berger K., Griese N., et al.: Int. J. Clin. Pharm. 36, 544 (2014).

17. Kwint H.F., Bermingham L., Faber A., Gussekloo J., Bouvy M.L.: Drugs Aging 30, 91 (2013).

18. Stewart M.: CMAJ 152, 1423 (1995).

19. Geurts M.M., Talsma J., Brouwers J.R., de Gier J.J.: Br. J. Clin. Pharmacol. 74, 16 (2012).

20. Lenander C., Elfsson B., Danielsson B., Midlöv P., Hasselström J.: Scand. J. Prim. Health Care 32, 180 (2014).

21. Vinks T., Egberts T.C., de Lange T.M., de Koning F.H.: Drugs Aging 26, 123 (2009).

22. http://www.nottingham.ac.uk/ pazmjb/ $\mathrm{nms} /$ downloads/report/files/assets/common/ downloads/108842\%20A4\%20Main\%20Report. v4.pdf (2014).

23. https://www.fip.org/www/uploads/database_file. php?id=319\&table_id= (2009).

24. Gillespie U., Mörlin C., Hammarlund-Udenaes M., Hedström M.: Int. J. Clin. Pharm. 34, 127, (2012).

25. Brulhart M.I., Wermeille J.P.: Int. J. Clin. Pharm. 33, 549 (2011).

26. https://www.farmkom.rs/farmkom.php?id=69 (2021).

27. http://isap.sejm.gov.pl/isap.nsf/download. xsp/WDU20011261381/U/D20011381Lj.pdf (accessed on 25 April 2021) (In Polish).

28. https://go.edqm.eu/ResPhCare20203 (2020). 